AlFONSO CaLderón

Nosotros, los de entonces

Ese año, fue lo de El Alamein, y un hombre gordo, igual que en la historia de Saroyan, murió de gordo. Ese año, conversábamos con frases hechas del tipo "de qué demonios hablas" o "sí, tienes un no sé qué". Ese año cantábamos As Times Goes Bye y De corazón a corazón. Ese año, enviábamos cartas en esquelas celestes, con diálogos de Hemingway, sin haber leido a Hemingway:

"- Te echo de menos, fui a varias fiestas y me lo llevé pensando en ti.

-Espléndido, querido, así volverás a mí antes del término del verrano.

-Claro, querida, te recordaré siempre"l.

Ese año, yo ya sabía que nunca en la vida habría de ser un hombre emprendedor, y me lo pasaba pensando en el origen del mundo y en el crimen de Alicia Bon Ese año, nes, partidarios de Rom gio Livingstone, de $\mathrm{Da}$ Lacordaire, y de Tihame Malena, los días de lluvi los aleros de los casas, toque mágico del agua de bamos fútbol hasta el a bamos la nariz, amábam ojos claros, que salían d tros nombres grabados rada inequívoca - en el a las doce del día, e iban nuestros chapuceros bi Odiábamos los consejos y llenábamos de cancion doscientas hojas: Lindo Percal, Sandalia de Plat Gricel, Virgen de Mediar 


\section{ADRIANA VALDÉS}

Es autora de los libros Composición de lugar - escritos sobre cultura (Editorial Universitaria, 1996), Memorias visuales - arte contemporáneo en Chile (Ediciones Metales Pesados, 2006), y Enrique Lihn: vistas parciales (Ediciones Palinodia, 2008, Premio Altazor de ensayo 2009). Junto a Ana María Risco, publicó los Escritos sobre arte de Enrique Lihn (Ediciones de la Universidad Diego Portales, 2008). Es miembro de número de la Academia Chilena de la Lengua (desde 1993), y subdirectora de la misma desde 2010. Desde 2002, en calidad de profesora invitada, integra el claustro académico del Doctorado en Filosofía con mención en Estética y Teoría del Arte, de la Facultad de Artes de la Universidad de Chile, donde ha dictado varios seminarios. 


\section{UNA PLUMA ÁGIL Y EMOCIONADA \\ Adriana Valdés}

Cuanto escribió Alfonso Calderón, en todos los géneros - poesía, diario, novela o biografía, libros sobre ciudades, libros de viajes- parte de su memoria, o mejor dicho, de sus memorias. Es probablemente el más insigne memorialista de la literatura chilena; y un memorialista como de la memoria involuntaria de Proust, siempre grácil y provocada por la circunstancia, nunca agobiadora como la de Funes. Si la de este personaje de Borges se le daba a la manera de un registro implacable y monótono, en Alfonso la memoria era azarosa y aventurera, e imprevisible, y saltaba de un tiempo a otro por senderos que iba descubriendo en las espesuras. Seguirlo es una fiesta para la inteligencia y una aventura de conocimiento.

Este texto, publicado en 1971 en Anales de la Universidad de Chile, se refiere a su memoria de adolescente, en los años cuarenta. Tiene la riqueza de los acontecimientos históricos de entonces, de las películas, de las canciones, de los dichos. Su curiosidad era ya infinita, y no se limitaba a su enorme amor por la literatura. Concentra este recuerdo en la primera lectura que lo saca de la niñez y lo proyecta, a él y a tantos otros de su generación, hacia la experiencia juvenil y adulta: el Crepusculario de "un Neruda sabio para los adolescentes de la tierra", el punto de quiebre hacia una sensibilidad poética renovadora. Les llega con retraso a estos jóvenes, pero los deja "marcados para toda la vida", así lo sienten y lo dice Alfonso. Con lecturas tan apasionadas como esta, fue construyendo una erudición notable y variopinta, capaz de abarcar desde los autores más prestigiosos a recuerdos triviales, tribales, generacionales, de esos que encienden las conversaciones.

Alfonso Calderón obtuvo en 1998 el Premio Nacional de Literatura por una obra vasta y variada, siempre memoriosa. "Nosotros, los de entonces" es una muestra de su pluma ágil, llena de humor y de emoción al mismo tiempo. El adolescente que recuerda estaba en Los Ángeles; había nacido en San Fernando, en 1930, y el trabajo de su padre lo había llevado a distintas partes de Chile. En Valparaíso, su familia materna, de origen siciliano, marca sus recuerdos de infancia. En Santiago, la Universidad, y el Instituto de Literatura Chilena, hasta 1973, además de las calles, los cines, los tangos y boleros, los lugares. ("Ya hablaremos de nuestra juventud", es un poema de Pedro Lastra sobre su generación y la de Alfonso). Notable estudioso de la literatura chilena, su recuperación de Joaquín Edwards Bello, de Martín Cerda y de Eduardo Molina Ventura, en uno de sus últimos y más notables libros, son, entre muchos otros trabajos, una muestra de su contribución fecunda y personalísima al conocimiento de nuestro país y sus letras. Su muerte el año 2009 fue la pérdida de un "mundo mago" de referencias, recuerdos y asociaciones, irremplazables y sorprendentes. Muchas de ellas, no todas, jay!, se encuentran en su amplia obra publicada. 


\section{Alfonso Calderón NOSOTROS, LOS DE ENTONCES}

Ese año, fue lo de El Alamein, y un hombre gordo, igual que en la historia de Saroyan, murió de gordo. Ese año, conversábamos con frases hechas del tipo "de qué demonios hablas" o "sí, tienes un no sé qué". Ese año cantábamos As Times Goes Bye y De corazón a corazón. Ese año, enviábamos cartas en esquelas celestes, con diálogos de Hemingway, sin haber leído a Hemingway:

"-Te echo de menos, fui a varias fiestas y me lo llevé pensando en ti.

- Espléndido, querido, así volverás a mí antes del término del verano.

-Claro, querida, te recordaré siempre".

Ese año, yo ya sabía que nunca en la vida habría de ser un hombre emprendedor, y me lo pasaba pensando en el origen del mundo y en el crimen de Alicia Bon. Ese año, nuestras cabezas albergaban muchos pensamientos a la vez y, frente a toda pregunta, respondíamos: "no estoy seguro"; aunque éramos capaces de repetir los primeros párrafos de las novelas que amábamos, como Miguel Strogoff (el correo del zar):

"-Majestad, un nuevo telegrama.

- ¿De dónde viene

- De Tomsk.

- ¿Está cortada la línea telegráfica más allá de esa ciudad?

- Está cortada desde ayer".

O como Kyra Kyralina, de Istrati:

"Aturdido, Adrián atravesó el corto bulevar de la Madre de Dios, en Braila, que conduce desde la iglesia del mismo nombre hasta el Jardín Público.

Cuando llegó a la entrada del Jardín, se detuvo, confuso y despechado:

- Sin embargo, exclamó en voz alta, ya no soy un niño... y creo tener derecho a comprender la vida y mi manera"

Ese año, éramos de If, de Mompracem, de un bar de Marsella, de Francia revolucionaria, de Cayena o de Paramaribo, éramos marxistas-leninistas, corporativistas, nipones, partidarios de Rommel, hinchas de Sergio Livingstone, de Daniel de la Vega, de Lacordaire, y de Tihamer Toth. Cantábamos Malena, los días de lluvia, arrimándonos bajo los aleros de los casas, para protegernos del toque mágico del agua del sur de Chile; jugábamos fútbol hasta el anochecer, nos rascábamos la nariz, amábamos a unas chicas de ojos claros, que salían del colegio con nuestros nombres grabados - con una tinta morada inequívoca - en el dorso de sus manos, a las doce del día, e iban conmoviéndose ante nuestros chapuceros balbuceos de amor. Odiábamos los consejos de nuestros padres y llenábamos de canciones los cuadernos de doscientas hojas: Linda Chilena, Frenesí, Percal, Sandalia de Plata, Cristal, Marión, Gricel, Virgen de Medianoche y, por supuesto, Dos Almas.

Odiábamos, o, para usar un lenguaje de entonces, nos importaba un carajo saber de Mazzini, León Gambetta, la garrucha diferencial, el dibujo a mano alzada, el círculo de Apolonio, el habitat de los ornitorrincos, la historia de los biotipos. Usábamos gomina Vanka, amábamos la oscuridad, los cigarrillos Premier corcho, el cinzano, los suspensores a rayas, los zapatos con hebillas y los feriados escolares, a cada muerte de obispo. Cambiábamos constantemente de criterio. Teníamos actores favoritos: Verónica Lake, Ella Raines, Rita Hayworth, Ronald Colman, Charles Boyer, Gary Cooper. Nos enamorábamos en cada primavera, "para toda la vida" y éramos felices, melancólicos, intempestivos, caballerescos, solitarios, prefiriendo, con devota lucidez, a la casa, la calle.

Primavera, la sangre altera. Los tilos de la Plaza de Armas de Los Angeles hacían reír y llorar de alegría al que estaba enamorado. Los Aliados recuperan París. Tres liceanos amamos la 
literatura, aunque no hemos todavía sentado a la Belleza en nuestras rodillas. Pedro Godoy nos desliza a mí y a Orlando Acevedo un libro forrado con papel morado, se pasa las manos por el pelo y enigmáticamente suelta un "ya verán ustedes". Acevedo y yo nos miramos. Al comenzar la clase de Matemáticas, miramos el libro bajo el banco. Se llama Crepusculario y, tras la lectura de Pantheos, sabemos que ingresamos a una secta, que vamos a estar marcados toda la vida, que ya no dormiremos nunca más tranquilos, que la notación erótica arranca disparada a no sabemos cuántos kilómetros por hora, que un paisaje interior nos muestra el vacío del mundo cuando dos ya no se aman. Nos preguntamos con Neruda si se va la poesía de las cosas o no la puede condensar mi vida, hicimos de Morena, la Besadora, nuestra Musa Perpetua, y nos prometimos odiar a los jefes de ojos turbios; liberaríamos a quienes vertían un raudal de llanto sobre cada noche de jergón malsano; entonaríamos, tomando en un peplo a nuestras amadas, Pelleas y Melisanda; toda la poesía estaba allí, en nuestras manos; era la Biblia, nuestro metro para el amor, un Neruda sabio para los adolescentes de la tierra, con la frase de entonces, repentinamente cursi, dijimos que era una maravillosa "arpa eólica"; nos llenamos los ojos de luz, parpadeando ante la fuerza de esa poesía voluntariamente distinta a toda la que antes leímos; retengo en mis ojos el deletreo pausado, lleno de sorprendida agitación, en esa mañana fría; retengo mis ojos encendidos, como cuando uno va a llorar; retengo la conciencia del tiempo que me vino de aquel "todo se va en la vida, amigos, y me parece que únicamente yo he de ver la mariposa de otoño, con la palabra inédita "volotear". Cambié a Tennyson y a Longfellow, a Dicenta y a Oscar Castro, por un Neruda garabateando en mi cuaderno con una letra nueva, homenaje a quien nos había despertado para siempre, a quien nos daba fuerzas, perturbándonos a puros te das cuenta, volviéndonos fragmentarios, primordiales y algo bergsonianos avant la lettre.

Me rompí el brazo ese año. Comí papas fritas todo el invierno. Me enamoré dos veces. Juré haber visto florecer la higuera en la noche de San Juan. Crecí tres centímetros. Fui a los bailes de la Laguna Esmeralda, sin fallar un sábado. Apareció en el pueblo una Mariposa Encantada, con una voz llena de consunción. Leo Marini me dio la mano, a la salida de un programa. Sin embargo, estoy seguro de que Crepusculario fue superior a todo eso y al Vuelo del Aguila, al zumbido de los tábanos, al olor indecible de los magnolios.

$\mathrm{Al}$ año siguiente, González Videla fue elegido Presidente, todos los hijos tuvieron problemas con sus padres, instalaron el Tribunal de Nuremberg, Cremaschi fue la mejor figura del equipo chileno de fútbol en el Sudamericano de Buenos Aires, y yo seguí amando Crepusculario, más, muchísimo más que las películas de Jorge Negrete y que los Ford amarillos, que mis primeros pantalones largos, plomo ratonados, y que Rita Hayworth cantando Amado Mío.

Uno tiene recuerdos, después de todo. 